\title{
The influence of digitalization on Chinese banks: new financial technologies in a plan economy
}

\author{
Igbal A. Guliev ${ }^{1, *}$, Alisa O. Khubaeva ${ }^{1}$, Elena A. Chernysheva ${ }^{1}$, and Irina V. Kolesova ${ }^{2}$ \\ ${ }^{1}$ MGIMO University, Prospect Vernadskogo, 76, 119454 Moscow, Russia \\ ${ }^{2}$ Sevastopol State University, Universitetskaya Street, 33, 299053 Sevastopol, Russia
}

\begin{abstract}
Nowadays, digitalization has become one of the most significant global development trends. The Chinese banking system, which has only recently been subjected to liberal reforms, is poorly researched in the viewpoint of the digitalization and financial technology impact on it. In this context, it is interesting to identify the main digitalization features in the PRC banking system and to identify this system's elements which are most susceptible to digitalization influence. The authors set the task to identify how digitalization changes the PRC banking system, in particular, how it affects shadow banking. The major challenges of the article are the high share of the closed data on the Chinese financial sector, the unclarity of the shadow banking activities in the country and their overall negative influence on the economy of PRC and Asian economies and the highly theoretical nature of the digitalization research of banking in the scientific community. The main article's results consist in that the main differences between digitalization and fintech are determined; it was also proved the Chinese banking system is more adaptable to changing conditions, and the authors suggested the main measures to reduce the shadow banking' share in China. The main contribution of the article is the revelation of the possible solutions to the problems of shadow banking in China through the use of the new financial instruments of the digital era.
\end{abstract}

\section{Introduction}

The Chinese banking system is interesting for research for a number of reasons: first, it represents a successful system, consisting of large banks, in a planned economy which is tightly regulated. Second, many Chinese banks (CNBC, ExIm Bank of China and others), $[16 ; 10]$, became transnational banks, despite opposition from the traditional major players in the market (American and European TNBs). Third, it is believed that the planned economy is inflexible, so it can be supposed it adapts to new realities slowly, wherein digitalization, especially in banking and financial technology, requires great adaptability for any bank. That's why it is very interesting what the prospects Chinese banks have and what they are doing to survive in a rapidly transforming world and a changing market landscape.

\footnotetext{
${ }^{*}$ Corresponding author: guliyevia@bk.ru
} 
Special attention should be paid to the problem of shadow banking, which is considered to be developed in China [14]. The main question is how new technologies will affect this sector, how it will change, and whether it will become completely digital, having gone into a slightly different space (both in the regulatory and in the physical sense). At the same time, it seems relevant to highlight what is meant by digitalization in the banking sector and to give its main differences from fintech. This is important because a number of large journals $[6 ; 2]$, consider these concepts to be close or even identical, which is true, but it is so only for the banking services end-user.

It is also necessary to notice that China has one of the most powerful banking systems among developing countries and this sector expansion to less developed countries, especially in Africa and Asia, causes the world community's worries as there is the market loss for its TNBs, but also due to a lack of confidence in China's banking sector's security and stability. All these factors make the research dedicated to the Chinese banking market extremely relevant.

\section{Literature review}

Digital transformation of banking is one of the new directions of the industry development. The key features of the process are reflected in [15], and in [12], where the key trends of the industry, such as cloud banking, digital customer experience, banking apps etc. are discussed. The main trends of the Asian banks are reflected in [7], but these trends are only partially right for China, as the PRC has its own complex way of the financial system development. The key trends in Chinese banks are reflected in [19], the authors pinpoint the competition on between the traditional banking institutions and e-traders, such as Alibaba. Another approach, which focuses on user experience is presented in (Paper 4). Based on this approach, the authors of this article put forward another idea of the interconnection of shadow banking in China and digitalization as an instrument of its legalization.

\section{Methodology}

First, it is necessary to understand the meanings of digitalization and fintech terms which are interrelated, but they are fundamentally different concepts. As mentioned earlier, these two phenomena for the final consumer look the same, but they should be understood differently (Figure 1).

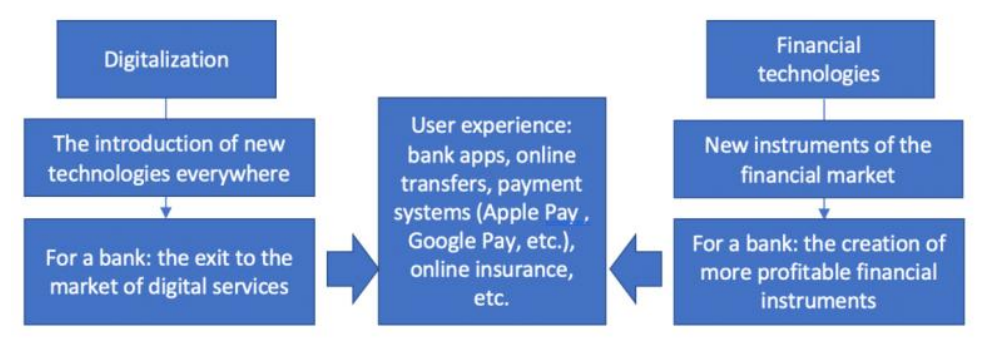

Fig. 1. Differences between digitalization and fintech (developed by the authors).

The second issue considered in the article is the PRC banking sector's present and future. To research this issue, it is necessary to evaluate the digitalization role in the PRC economy from the viewpoint of where it comes from: whether it comes from inside or it is an element borrowed from foreign companies. That's why the authors divide digitalization into internal and external. In addition, the authors conduct a regression analysis of the 
foreign banks' role in the Chinese economy; through this analysis, it is proved that the PRC economic system differs that digitalization from the inside and from the outside are harmoniously combined in it.

The third stage of the research is the study of shadow banks in the PRC: using this basis, the authors develop recommendations for the further digitalization development in the PRC banking sector, taking into account the need to reduce the shadow banks' role. An empirical shadow banking' research is based on a sector's statistical analysis, made by BIS.

\section{Chinese banks prospects and adaptivity}

For the Chinese banking market, innovativeness, directed from the inside, is not characteristic. This is due to the fact that for a long time the financial services market, including banking, was regulated by the state and innovations in this area were not needed, as the financial technologies development was associated with increased risks, and it was also associated with increased corporate profits; this situation within the planned economy is disadvantageous to the main beneficiary which is the state. Nevertheless, recently a high degree of the financial sector and the economy's interdependence has created the need for more advanced financial instruments; the society's technological development and an access level increase for Chinese people to information created the need to suit to the current realities and to stimulate economic development through domestic demand [5]. The Internet merchants companies became the first ones, reacted to the changing situation, for example, Alibaba, which created a successful digitalized corporation's model and financial service AliPay, as well as Tencent with its WeChat Pay. These alternatives creation to classical banking led to a decrease in its popularity; a specific assessment is given by S\&P [3]. But it can be noticed that fluctuations in the issue of bank cards emission were at 5-7\% in the first months after each service release. Thus, Chinese banks needed to catch up with companies in the real sector in the digital services provision. All foregoing was the result of liberal reforms in the banking sector and the Western banks' penetration into the Chinese market.

Nevertheless, Western banks are not ready to actively participate in China's economic development; and the Chinese economy's priority sectors in the viewpoint of development goals are of little interest to them. Besides Western banks' functioning model is not adapted to Chinese realities. That's why, today, most of the digitalization and its attendant changes are realized by Chinese banks themselves, and at the same time quite efficiently (Figure 2).

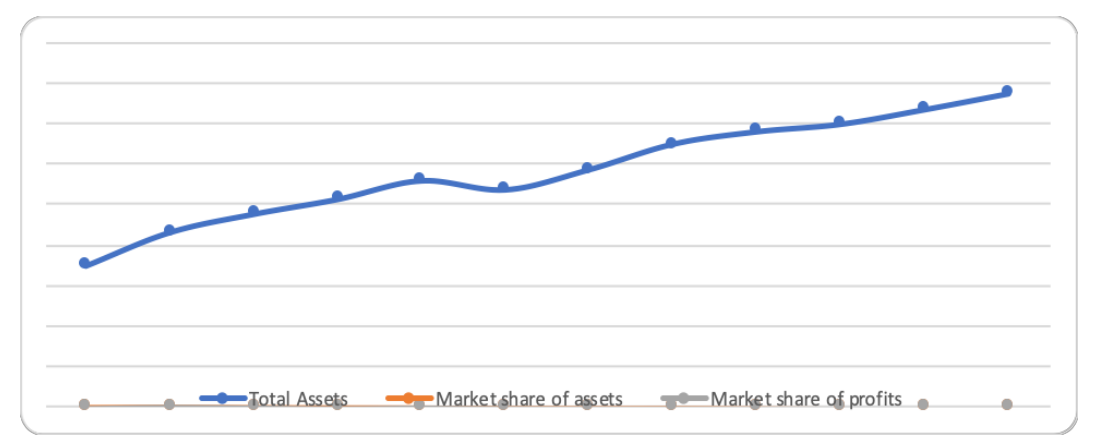

Fig. 2. The foreign banks' position in the Chinese market (compiled by the authors), billion renminbi, [1].

Thus, digitalization from the inside and outside is quite harmoniously combined in the Chinese economy and it is realized mainly through the several Chinese corporations' 
finances - Alibaba, Tencent, Xiaomi (Xiaomi Finance), Yillion) [18]. These companies try to occupy foreign markets.

Chinese banks, despite the planned economy where they exist, turned out to be highly adapted to modern realities, moreover, the risks inherent in their activities were moderate [3], at the level of developed countries' banks. It is necessary to notice that the technological revolution takes place in China's economy [1], that's why the PRC economy's digitalization is very high. It is necessary to notice that the level of economy's digitalization correlates with the level of banks' adaptability in the case of the PRC, so the authors suppose that digitalization is not a process, but it is a kind of public institution, characterized by blurred outlines, but specific manifestations.

\section{Shadow banking and digitalization in China}

The shadow banking volume in China is still difficult to determine accurately, probably, it occupies from 50 to $65 \%$ of GDP in the PRC economy [4]. This is a very large share of the shadow sector, which is practically not regulated by the state; this fact creates significant problems in the realization of the state monetary policy.

Digitalization is making adjustments to the shadow sphere: if earlier it was a question of creating a loan from assets which were not controlled by state supervisory authorities, now the demand for shadow credit has also increased because of speed increase of the money circulation. At the same time, digitalization allows state control authorities to clearly specify financial flows and organize control over the funds' movement. This measure has made the shadow banks' existence much more difficult [11]. In the whole, digitalization has more positive than negative effects here: the shadow banking growth in China has slowed down [17], but still, its share remains high, especially in lending households and socially significant projects.

The authors suppose that the digitalization effects have not yet fully manifested themselves, as the Chinese economy is characterized by a lag between the industry regulation strengthening and the search for new ways to avoid it. With high probability, shadow banks will soon turn to new loan generation sources, for example, to cryptocurrency, or to Western partners who will be ready to act as trust funds. In fact, there are much more schemes for using digital technologies in the financial sphere than the possibilities for their regulation by financial monitoring bodies. At the same time, we should expect an increase in the shadow banks' share in the PRC economy in the future, as the shadow sector plays the stimulator role for a number of PRC economy's sectors; consequently, in the conditions of a PRC economy's slowdown, the shadow sector regulation will be relaxed with a high probability.

\section{Discussion}

As the current trends' analysis of the Chinese banking system development shows, the Chinese banking system is highly adaptable but it has insufficient control level. This leads to the fact that the Chinese shadow sector of the banking system is the largest in the world. It is also necessary to understand that current banking system development trends are determined by the digitalization and financial technologies development. As it was said, digitalization and fintech give not only negative but also positive changes in the situation. The authors propose ta take a set of measures to reduce the shadow banking impact on the Chinese economy while maintaining the positive effects that it gave China in terms of economic development. 
1) It is necessary to create a system for monitoring financial transactions in the country in the Internet sphere and oblige banks to generate reports on suspicious transactions. As a number of large banks in China have subsidiary banks operating in the shadow sector [13; 18]. The same task must be entrusted to the PRC financial control service, but for transactions which were not declared suspicious. Due to the extremely high volume of data, it is required to develop an automated transaction control system based on Big Data algorithms.

2) It is necessary to integrate the financial Chinese trading companies' innovations in China's financial sector. It is necessary to combine financial and trading services under one umbrella brand: Alibaba has managed to realize it, but, for example, Tencent is not a tangible goods seller, that's why, it is logical, for example, to form a WeChat Pay block Xiaomi Finance or to create new electronic platform commerce such as Aliexpress. In general, this measure is aimed at definancialization the economy and the payment sector to be out of the shadows; such giants as the listed companies will carry out financial monitoring on their own.

3) It is necessary to create a consumer lending system, microloans, and social lending systems in a transparent economy's sector, without a shadow loan use. To do this, the services of the same companies which were proposed above can be used; for example, to create an investment platform for small enterprises on the basis of Aliexpress, or a social lending fund on the basis of companies' financial mechanisms. If the company creates this social lending fund, the state can ease its tax burden; in this case, this measure may attract big companies such as Huawei and Xiaomi which are two largest digitalization drivers in China and owners of their own financial innovations.

4) It is necessary to develop legislation in the field of foreign banking enterprises in China. This will allow using foreign banks' borrowed financial resources, but at the same time, there won't be an increase of foreign agents' influence on the Chinese economy.

The proposed recommendations are measures which will allow the PRC economy to reduce transaction costs and to be more competitive in the digitalized world. At the same time, the real sector development lies in the Chinese economy's heart. This fact differs China's economy from the developed countries' economies where digitalization was based on the economy of services. That's why the digitalization models of the Chinese economy should also be based on the cost reduction of the real sector companies. These measures will allow to reduce the negative finance effects, which has recently been observed in Asia and China in particular $[9 ; 8]$.

\section{Discussion}

The research showed that digitalization and fintech are concepts, although similar, but differing in essence: if fintech are new tools, being used to make more profit in the financial market, then digitalization is a process which is characterized by the widespread new technologies use.

The second significant result was proof that the Chinese banking system is not so closed as it seems during its initial consideration: its digitalization goes both inside and out. At the same time, these two processes harmoniously complement each other but can cause serious changes in the country's economy if the shadow sector which they stimulate is not taken under control.

The Chinese economy's shadow sector is the biggest problem of China's financial system. This problem's solution lies in creating alternatives to the shadow sector's tools through the real sector companies' tools. Digital technologies should become an important element in the fight against the shadow banking sector. They will make it possible to bring this sector's operations into a transparent economy. To avoid the inefficient public 
resources use, it is possible to use the non-financial sector companies' tools which they use in order these technologies to penetrate into consumer and social lending, which are most heavily connected with the shadow sector.

\section{References}

1. A. Gilder, J. Chan, A. Jiang, L. Chew, How China's financial liberalization can unlock new opportunities (2019) https://www.ey.com

2. Digital and innovation. https://www.ey.com

3. F. Wang, Tech Disruption In Retail Banking: China's Banks Are Playing Catch-Up To Big Tech (2019) https://www.spglobal.com

4. G. Sun, BIS Working Papers, 822 (2019) https://www.bis.org

5. A. Gupta, C. Xia, International Symposia in Economic Theory and Econometrics, 25, 215 (2018)

6. H. Forest, D. Rose, Global Transaction Banking (2015) https://cib.db.com

7. J. Dahl, J. Sengupta, How Asia is reinventing banking for the digital age (2020) https://www.mckinsey.com

8. J. Shu, C. Zhang, N. Zheng, International Review of Economics \& Finance, 69, 1106 (2020)

9. J. Wang, International Journal of Communication, 11, 581 (2017)

10. J. Calkins, Banking Abroad: The Globalization the Chinese Banks (2013) https://knowledge.ckgsb.edu.cn

11. J. Gruin, P. Knaack, New Political Economy, 25(2), 1 (2019)

12. A. Karagiannaki, G. Vergados, K. Fouskas, MCIS 2017 Proceedings, 2 (2017) http://aisel.aisnet.org

13. K. Tsai, Issues \& Studies, 51(1), 55 (2015)

14. M. Chui, C. Upper, SUERF Policy Note Issue, 20, 1 (2017) https://www.suerf.org

15. OECD. Digital Disruption in Banking and its Impact on Competition (2020) http://www.oecd.org

16. Z.Y. Shu, S.-Y. Tsang, T.X Zhao, Open Journal of Business and Management, 8, 68 (2020)

17. T. Ehlers, S. Kong, F. Zhu, BIS Working Papers, 701 (2018) https://www.bis.org

18. V. Shiao, China digibank players are old hands in search of fresh pastures (2020) https://www.businesstimes.com.sg

19. Z. Shu, S. Tsang, T. Zhao, Open Journal of Business and Management, 08(01), 68 (2020) 